\title{
An Interaction of learning and teaching styles influencing mathematic achievements of ninth-grade students: A multilevel approach
}

\author{
Suntonrapot Damrongpanit \\ Department of Educational Basic and Development, Faculty of Education, Chiang Mai University, Chiang Mai, Thailand \\ Received 04 October, 2013; Accepted 12 September, 2014

\begin{abstract}
The purposes of this study were to explore students' learning styles and teachers' teaching styles and study the effects and interaction effects of learning styles and teaching styles on mathematics achievements. The subjects were 3,382 ninth-grade students and $\mathbf{1 1 0}$ mathematic teachers. The main results revealed that most students were categorized in the reflector style (26.11\%), whereas most teachers were categorized in the facilitator style (34.55\%). Also, the two groups of learning styles and the three groups of teaching styles had direct effects significantly, and they had $76.47 \%$ interaction effects in all matching between them (30.77\% matching and $69.23 \%$ mismatching) on mathematic achievements. The theorist students were the most advantageous group whereas the reflector students were the most disadvantageous group of learning styles in learning mathematics.
\end{abstract}

Key words: Learning styles, teaching styles, mathematics achievement, multilevel analysis, moderating effect, interaction effect.

\section{INTRODUCTION}

Mathematics is an important subject for science and technological careers but many students still have difficulties and poor performance in the subject and failure in learning it (Peker, 2009; Education, Audiovisual, and Culture Executive Agency, 2011). The foundations of students' learning mathematics are particularly complex and depend upon numerous factors from students, families, teachers, and schools. Researchers and educators have been trying to depict the factors affecting the learning outcome in mathematics and found interesting factors including learning styles, teaching styles, and interaction effects, either positive (matching) or negative (mismatching) effects (Zhang, 2005; Yazicilar and Güven, 2009; Khandaghi and Farasat, 2011; Sriphai et al., 2011).

There has been a great deal of research about learning style in education. For example, Duff (2001) defined a learning style to be the composite of characteristics cognitive, affective, and psychological factors that serves as an indicator of how an individual interacts with and

\section{E-mail: suntonrapot.d@c mu.ac.th}

Authors agree that this artic le rema in pemanently open access under the terms of the $\underline{C}$ reative Commons Attribution License 4.0 Intemational Lic ense 
responses to individual differences. Entwistle (1991) Cassidy (2004) and Tulbure (2012) defined learning style as a habitual process of perceiving and thinking. It is qualitatively distinct and associated with personality, affection, and motivation characteristics; moreover, it is an important factor to predict students' success in classroom activities and future learning. The learner with strong learning style preference can especially benefit in academic outcomes (Altun and Yazici, 2010). However, not all students learn the same way; therefore, it becomes imperative that teachers realize the learning style differences and teach in a manner in which all learning styles are incorporated (Cano et al., 1992) to ensure that the largest number of students can learn equally and effectively. Allinson and Hayes (1988) and Butler (1988) state that identifying individual students' learning characteristics may both help the students to be aware of their strength and weakness in the subject matter and also help the educators to improve their course design and choose helpful and appropriate learning outcomes. However, not only learning styles affects the student outcomes, but the teaching styles also have important role to improve the students' outcomes.

Teaching styles are teaching roles comprising attitudes, behaviors, preferred methods and techniques (Vaughn and Baker, 2001; Visser et al., 2006). They can vary between a lecturer/teacher-centered approach and a student/learner-centered approach based on a teacher's thoughts, ability, and beliefs about what constitutes a good teaching (Alhussain, 2012). Some teachers believe that a class should be teacher-centered, where the teacher is the expert and authority in presenting information. In contrast, others take a learner-centered approach, where teachers view their role more like a facilitator for students learning. Teaching style awareness may also impact on the classroom setting, activities assessment, and teacher-student interactions which become information for better understanding, changing, modifying, and supporting to improve their interaction with students while maintaining all contextual aspects of teaching. Due to the various types of both teaching styles and learning styles in every classroom, many educators have suggested that learning and teaching styles interaction might reduce inequality of learning by getting more information of their matching styles (Vermunt and Verloop, 1999; Lage et al., 2000; Alhussain, 2012).

Many recent studies have confirmed that there are causal relationships between learning and teaching styles from "matching" and "mismatching" on their student achievements (Vosser et al., 2006; Perterson et al, 2009; Naimie et al., 2010; Kinshuk et al., 2010). They have hypothesized that matching is considered as the congruence between the learner, the lecturer and the subject matter (Hayes and Allinson, 1996; Ford and Chen, 2001, Damrongpanit et al., 2013) which affect positive learning outcomes. Mismatching is between the preferred learning styles, the nature of the subject matter and teaching method which would result in lower motivation, poorer performance and perhaps in attrition (Felder and Silverman, 1988; Akdemir and Koszalka, 2008; Rahimi and Asadollahi, 2011). Several studies suggested that matching may be significantly more effective in creating a learning environment that is conductive to learning than mismatching (Nor, 2006). According to the literature review, it is clear that learning style and teaching style are closely congruent with student development, and it is possible for each class to achieve the development together both in matching and mismatching. However, when teachers apply this knowledge in the classroom, they have to be careful about their teaching styles because they may mismatch particular student learning style in order not to have negative effects of mismatching. This is because recent studies did not show clear results of the interaction effect of style by style (Ford and Chen, 2001). In addition, there has been limitation concerning the scope of research in terms of subject matters and methodology (Peterson et al., 2009; Ghada et al., 2011), so it is difficult to apply the results to the subject matters which are necessary for the development of students' basic skills such as mathematics, science and linguistics.

Thailand is one of the countries trying to solve the problems of students' learning achievement. As a result of a study of the knowledge on learning style and teaching styles, the researchers could explain the problems caused by mismatching which is ignored in the classroom. This can be seen by the continuous assessments which show low learning achievement and learning skills resulting in students' skipping classes, negative attitude towards learning, and conflict and violence in schools. These problems tend to continue although there have been a variety of developments of learning management. The researcher has summarized the literature review and thinks that this research finding would bring up a new different perspective for revising and supplementing the policy more carefully and efficiently than ever.

\section{Objectives}

The two research objectives were 1) to explore the students' learning styles and teachers' teaching styles and 2) study the effects of the learning styles and teaching styles on mathematics achievements.

\section{Research hypothesis}

Based on the literature review, the learning and teaching styles were dominantly a character on their own in the definition. Therefore, it was hypothesized for the effects and the interaction effects (matching) as follows: 1) the theorist student had the highest effect on mathematic 
achievement; 2) the expert teacher had the highest effect on students' mathematic achievement; and 3) the positive (matching) and negative (mismatching) interaction effects comprised the expert teacher matched with the theorist and the pragmatist students, the formal authority teacher matched with the activist and the theorist students but mismatched for the reflector and the pragmatist students, the personal model teacher matched with the activist and the theorist students but mismatched for the reflector and the pragmatist students, the facilitator teacher matched with the activist and the pragmatist students but mismatched for the theorist and the reflector students, and the last group, the delegator teacher matched with the pragmatist and the reflector students but mismatched with the theorist and the activist students.

\section{LITERATURE REVIEWS}

\section{Learning styles}

Learning styles were the individual's natural or habitual pattern of acquiring and processing information in learning situations. A core concept is that individuals differ in how they learn. The idea of individualized learning styles originated in the 1960s, and has been the focus of such a lot of research and practitioner-base studies in the area. There are a variety of definitions, theoretical positions, models, interpretation and measures of the construct (Beck, 2001; Cassidy, 2004). The well-known and most implemented work was conducted and inspired by Witkin (1962) and Pask (1972) who proposed the global/analytic differences in a very wide range of human activity from basic perception to career choice. Pavio (1971) proposed the verbalizer/visualizer to investigate cognitive personality, Kolb (1984), Honey and Mumford (1996), and Vermunt (1994) proposed the learning style models emphasizing the students' information processing and learning centered method. Dunn et al. (1989) and Keefe and Monks (1986) proposed the learning style model emphasizing instructional preference and social interaction. Although there were various approaches, Honey and Mumford learning style investigation which is widely cited and issued in education and training, emphasized view about information processing. Peterson et al. (2009) have summarized studies in this area and found out that approximately 27 percent recommend this concept.

Based on Kolb's Experiential Learning Model (ELM) (1984), which consists of two dimensions between information receiving (which explains concrete experimentation and abstract conceptualization), and information processing (which explains active experimentation and reflective observation) (Rayner and Riding, 1997). Honey and Mumford devised a new model which was specifically aimed at middle/senior manager in business. Their reasoning was that Kolb's framework seemed to have little validity with the manager, and it was far more preferable to the quiz managers on their general behavioral patterns than to ask them upfront how they go about to learn. Their model involved two adaptations to Kolb's framework, reworded the stages in the learning cycles to be applicable to the managerial experiences of decision-making and problem-solving: having experience, reviewing and reflecting on the experience, concluding and drawing their own conclusion, and planning the next steps by putting the theory into practice. Then, they proceeded to align the stages with specific characteristics, namely the Activist (ACTV) (Kolb's active experimentation) defined as one who learns by doing, needs to get their hands dirty, and dive in with both feet first. Having an open-minded approach to learning, involving themselves fully and without bias in new experiences, the Theorist (THEO) (Kolb's abstract conceptualization) is one who likes to understand the theory behind the actions. They need models, concepts and facts in order to engage in the learning process. Preferring to analyze and synthesize, drawing new information into a systematic and logical 'theory', the Reflector (REFC) (Kolb's reflective observation) is one who learns by observing and thinking about what happened. They may avoid leaping in and prefer to watch from the sidelines. Preferring to stand back and view experiences from a number of different perspectives, collecting data and taking the time to work towards an appropriate conclusion, and the Pragmatist (PRAG) (Kolb's concrete experience) is one who needs to be able to see how to put the learning into practice in the real world. Abstract concepts and games are of limited use unless they can see a way to put the ideas into action in their lives (Visser et al., 2006). It is important to note that Honey and Mumford considered these traits to be adaptable and acquired preferences - and not fixed personality characteristics.

\section{Teaching styles}

Teaching styles also vary as much as learning styles do, but they have been written about less than learning styles. Teachers have different strengths and preferences with regards to how they develop an individual's learning and learning styles (Visser et al., 2006). Some instructors give lectures, while others demonstrate or discuss. Some focus on rules, and others on examples. Some emphasize memory, and others understanding.

Teaching style is expressed through the behaviors, characteristics and mannerisms that reflect teachers teaching philosophy and the role the teachers prefer to take when conveying information in a classroom. It is defined based on four components including creation, continuity, effectiveness, and evaluation (Khandaghi and Farasat, 2011). The most common teaching styles inventory was developed by Grasha and Riechman (1996) who 
identified five potential approaches for classroom teachers: the Expert (EXPT), defined as one who possesses knowledge and expertise oversees, guides, and directs learners, gains status through knowledge, and focuses on facts; the Formal Authority (AUTH), defined as one who possesses status among learners because of knowledge and authority or position, follows "traditions" and standards of medical practice, focuses on rules and expectations for learners, and supervises learners closely with critical eye toward standard practices and procedures; the Personal Model (PMOD), defined as one who leads by personal examples, suggests prototypes for appropriate behavior in office, shows learners how to do things, and wants learners to observe and emulate approach; the Facilitator (FACT), defined as one who emphasizes personal nature of teaching-learning relationship, asks questions, explores options with learners, and focuses on learner responsibility, independence and initiative; and the Delegator (DELG), defined as one who encourages learner responsibility and initiative when appropriate to have a learner function autonomously, takes the role of a "resource person", answers questions, and periodically reviews a learner progress. In sum, it could approximately be divided into to two styles: teacher-centered style (direct), which consists of Expert, Authority, and Personal Model, and learningbased style (indirect), comprising Facilitator and Delegator (Khandaghi and Farasat, 2011)

\section{Matching of learning and teaching styles}

A considerable amount of research suggests that matching the teaching and learning styles, an individual's learning style preference to specific learning activity, will help to enhance students' outcomes. Although they have a perfect congruence in findings, Peacock (2001), Vosser et al. (2006) Naimie and friends (2010) and Kinshuk et al. (2010) assert that students' and teachers' styles are better matches, for students are likely to work harder both in and outside the classroom, and also to benefit much more from their learning outcomes. Reid (1996) suggests that matching the teaching style with the learning style gives all learners an equal chance in the classroom, and builds student self-awareness. In contrast, Felder and Spurlin (2005) state that when mismatching, the students may become bored and inattentive, do poorly on test, get discouraged about the course and the curriculum. In addition, they themselves, in some cases, change to other curricular or drop out of school. For this reason, it has been suggested that teachers should be aware of their styles and help students to identify their learning styles. Attention to learning and teaching styles has been described as part of the desirable trend toward learningcentered and "need-based instruction". It has also been suggested that teachers should help students to identify their learning styles and become more flexible (Peacock,
2001; Visser et al., 2006; Yazicilar and Guven, 2009; Naimie el al., 2010; Ghada el al., 2011) and make equal chances to learn in the classroom. This results in an efficient teaching and learning process (Reid, 1996).

However, although many of the research results have shown the important impact of both the teaching and the learning style, there is still unclear evidence of how to implement them. Most of the researches on the teaching and the learning styles have been cross-sectional in nature (Visser et al., 2006). Many of the studies were conducted in higher education (Peacock, 2001; Visser et al., 2006; Naimie et al., 2010; Ghada et al., 2011; Kinshuk et al., 2009), in specific courses such as English, accounting or online courses (Peacock, 2001;Naimie et al., 2010; Visser et al., 2006; Ford and Chen, 2001). However, they showed only the results with significant statistics due to small sample size (Ghada et al., 2011; Kinshuk et al., 2009). They could not explain which pair of the learning and teaching style was matching and mismatching (Ford and Chen, 2001; Naimie et al., 2010, Ghada et al., 2011), and showed the matching of learning style of student and learning style of teacher instead of matching learning and teaching styles of the students and the teacher. Hence, inside the classroom, there is the challenge of appreciating how various instructional approaches and fields of studies interact with students of different abilities and variable attitudinal orientations. Therefore, it is not only difficult to explain the stability, the type of matching and mismatching style but also to clarify conclusions in different subjects.

\section{METHODOLOGY}

\section{Participants}

The data were collected from 3,382 ninth-grade students $(38.60 \%$ boys and $61.40 \%$ girls) who enrolled in the academic year of 2012 and, correlated with, 110 mathematics teachers in the north east area of Thailand. These subjects were selected by multistage random sampling.

\section{Instruments}

1. The Learning Style Questionnaire (LSQ) based on Honey and Mumford's learning style questionnaire (1996) which was designed to evaluate the comparative strengths of the four students' learning styles: Activist (ACTV), Theorist (THEO), Reflector (REFC), and Pragmatist (PRAG) was adapted by translating LSQ, which comprised 80 items (divided in 20 items for each learning style), in the Thai language. The meaning of each sentence was checked by the English language specialists and was tried out with 71 ninthgrade students. According to the four learning styles scoring and unifying the discrimination index by item-total correlation method between $\left(r_{x y}\right)$ 0.263-0.732 at .05 significant level, the reliability $(\alpha)$ for each learning styles was $0.831,0.822,0.870$, and 0.860 respectively.

2. Teaching Style Inventory (TSI) in the Thai language version based on Grasha's Teaching Style Inventory (2002) was designed to evaluate the comparative strengths of the different five teachers' 
Table 1. Result of learning and teaching styles survey.

\begin{tabular}{|c|c|c|c|c|c|}
\hline \multirow{2}{*}{ Teaching Styles } & \multicolumn{4}{|c|}{ Learning Styles } & \multirow{2}{*}{ Total } \\
\hline & ACTV & THEO & REFC & PRAG & \\
\hline EXPT $(33)^{a}$ & 310 & 252 & 254 & 279 & \\
\hline$(30.00 \%)$ & $(9.17 \%)$ & $(7.45 \%)$ & $(7.51 \%)$ & $(8.25 \%)$ & $1,095(32.38 \%)$ \\
\hline AUTH $(7)^{a}$ & 45 & 63 & 64 & 36 & 208 \\
\hline$(6.36 \%)$ & $(1.33 \%)$ & $(1.86 \%)$ & $(1.89 \%)$ & $(1.07 \%)$ & $(6.15 \%)$ \\
\hline $\operatorname{PMOD}(16)^{\mathrm{a}}$ & 68 & 54 & 81 & 96 & 299 \\
\hline$(14.55 \%)$ & $(2.01 \%)$ & $(1.60 \%)$ & $(2.40 \%)$ & $(2.84 \%)$ & (8.81\%) \\
\hline FACT $(38)^{a}$ & 263 & 272 & 329 & 373 & 1,237 \\
\hline$(34.55 \%)$ & $(7.78 \%)$ & (8.04\%) & (9.73\%) & $(11.03 \%)$ & $(36.58 \%)$ \\
\hline DELG $(16)^{a}$ & 128 & 162 & 155 & 98 & 543 \\
\hline$(14.55 \%)$ & $(3.79 \%)$ & $(4.79 \%)$ & $(4.58 \%)$ & $(2.90 \%)$ & $(16.06 \%)$ \\
\hline Total $(110)^{a}$ & 814 & 803 & 883 & 882 & 3,382 \\
\hline$(100 \%)$ & (24.07\%) & (23.74\%) & (26.11\%) & (26.09\%) & $(100 \%)$ \\
\hline
\end{tabular}

Note: ${ }^{a}$ number of teachers.

teaching styles: Expert (EXPT), Authority (AUTH), Personal Model (PMOD), Facilitator (FACT), and Delegator (DELG). The TSI, which consisted of 40 items (divided in 5 items for each teaching style) in Thai language was checked by the English language specialists and was tried out with 40 teachers involved with ninth-grade students. The result of TSI revealed that the discrimination index by item-total correlation method between $\left(r_{x y}\right)$ 0.263-0.732 and the reliability $(\alpha)$ for each teaching styles were $0.789,0.757,0.869$, 0.896 , and 0.757 , respectively.

3. The Mathematic Achievement Test, which consisted of 30 items in multiple choices, was tried out, and the results showed that the difficulty of items $(p)$ and the discrimination $(r)$ were ranged from $0.212-0.647$ and $0.222-0.889$ respectively, and the reliability (KR20) was 0.873 .

\section{Data collection and analysis}

The students were given one hour to complete the test and unlimited time to complete the LSQ under the suggestion of the researcher. Then the data structures between students' achievements and learning styles and teachers' teaching styles were organized. For the teachers, they were given unlimited time to complete the TSI. The answers from LSQ and TSI were checked and used as dummy variables to indicate only one learning style for each student and only one teaching style for each teacher. The student and the teacher received 1 when they had the highest mean score of learning or teaching style, based on scoring on the prototype questionnaire criteria, and 0 for the rest of the lower mean score of learning or teaching styles. For mathematic achievement, the researcher used composite raw scores to analyze the hypothesis model.

Cross-tabulation analysis was used to explore the learning styles and the teaching styles. Multilevel regression analysis with the random slope was used to study effects of learning and teaching styles and interaction effects between them on achievement by using Mplus program (version 7).

\section{FINDINGS}

The main research results were as follows:

According to the learning and teaching style survey, it was found that 3,382 ninth-grade students were categorized in each learning style closely ranging from 23.74 to $26.11 \%$. The biggest group of students appeared to be in the REFC style, whereas the smallest group was in the THEO style. For 110 mathematics teachers, it was found that there was a different proportion between each style ranging from 6.36 to $34.55 \%$. The biggest groups of teachers closely appeared to be in the FACT and the EXPT styles, whereas the smallest group was in the AUTH style (Table 1).

From the multilevel regression analysis, the results showed that the intraclass correlation (ICC) of mathematics achievement was 0.556 . The model showed the goodness of fit with $L R=-8484.943, A I C=17031.887$, $B I C=17221.799$, and $A B I C=17123.298$.

As for the learning and teaching style effects, the mean of slopes of THEO and PRAG, or mean of regression coefficients from learning styles on mathematic achievements, was positively statistical significant at .01 level (2.555 and 1.908 respectively). In the teacher level, three regression coefficients from the teaching styles on classroom mathematic achievements which consisted of DELG, PMOD, and FACT were positively statistical significant at .01 level $\left(b_{D E L G}=10.631, b_{P M O D}=3.758\right.$ and $b_{\text {FACT }}=3.342$ ).

In relation to the interaction effects of learning and teaching styles, the 13 out of 17 interaction effects $(76.47 \%)$ were statistical significant at 0.05 level (Table 2; Figure 1). They can be divided into 4 positive effects or "matching" $(30.77 \%)$ and 9 negative effects or "mismatching" $(69.23 \%)$ on students' achievement. The ACTV students were matching with the AUTH $\left(b_{A U T H}=3.029\right)$ and the FACT $\left(b_{F A C T}=1.177\right)$ teachers, but they were mismatching with the DELG $\left(b_{D E L G}=-3.332\right)$ and the PMOD ( $\left.b_{P M O D}=-0.697\right)$ teachers. The THEO students were matching with the EXPT $\left(b_{\text {EXPT }}=2.356\right)$ and the DELG $(b D E L G=1.026)$ teachers, but they were 
Table 2. Effects and interaction effects of learning and teaching styles on mathematics achievement.

\begin{tabular}{|c|c|c|c|c|c|}
\hline DV & IV & b & S.E. & $z$ & p-value \\
\hline $\begin{array}{l}\text { Student Level } \\
\text { Residual } \\
\text { Teacher Level }\end{array}$ & - & $7.340^{* *}$ & 0.679 & 10.810 & 0.000 \\
\hline Intercept & $\begin{array}{l}\text { MATH } \\
S_{\text {ACTV }} \\
S_{\text {THEO }} \\
S_{\text {RECT }} \\
S_{\text {PRAG }}\end{array}$ & $\begin{array}{c}6.178^{\mathrm{a}} \\
0.918 \\
2.555^{\star *} \\
1.277 \\
1.908^{* *}\end{array}$ & $\begin{array}{l}0.000 \\
0.853 \\
0.898 \\
0.922 \\
0.507\end{array}$ & $\begin{array}{c}999.000 \\
1.076 \\
2.844 \\
1.384 \\
3.763\end{array}$ & $\begin{array}{c}999.000 \\
0.282 \\
0.004 \\
0.166 \\
0.000\end{array}$ \\
\hline $\begin{array}{l}\text { MATH } \\
\text { (Classroom Achievements) }\end{array}$ & $\begin{array}{l}\text { EXPT } \\
\text { AUTH } \\
\text { PMOD } \\
\text { FACT } \\
\text { DELG }\end{array}$ & $\begin{array}{c}0.149 \\
1.000^{a} \\
3.758^{\star \star} \\
3.342^{\star *} \\
10.631^{\star \star}\end{array}$ & $\begin{array}{l}1.088 \\
0.000 \\
1.120 \\
1.017 \\
1.168\end{array}$ & $\begin{array}{c}0.137 \\
999.000 \\
3.356 \\
3.286 \\
9.104\end{array}$ & $\begin{array}{c}0.891 \\
999.000 \\
0.001 \\
0.001 \\
0.000\end{array}$ \\
\hline $\begin{array}{l}S_{\text {ACTV }} \\
\text { (Mean of slope from ACTV to MATH) }\end{array}$ & $\begin{array}{l}\text { EXPT } \\
\text { AUTH } \\
\text { PMOD } \\
\text { FACT } \\
\text { DELG }\end{array}$ & $\begin{array}{c}0.148 \\
3.029^{\star *} \\
-0.679^{*} \\
1.177^{\star *} \\
-3.332^{* *}\end{array}$ & $\begin{array}{l}0.341 \\
0.998 \\
0.324 \\
0.338 \\
0.733\end{array}$ & $\begin{array}{c}0.434 \\
3.035 \\
-2.098 \\
3.479 \\
-4.545\end{array}$ & $\begin{array}{l}0.664 \\
0.002 \\
0.036 \\
0.001 \\
0.000\end{array}$ \\
\hline $\begin{array}{l}\text { STHEO } \\
\text { (Mean of slope from THEO to MATH) }\end{array}$ & $\begin{array}{l}\text { EXPT } \\
\text { AUTH } \\
\text { PMOD } \\
\text { FACT } \\
\text { DELG }\end{array}$ & $\begin{array}{c}2.365^{* *} \\
-2.260^{* *} \\
-2.555^{* *} \\
-0.978^{* *} \\
1.026^{*}\end{array}$ & $\begin{array}{l}0.235 \\
0.187 \\
0.618 \\
0.197 \\
0.475\end{array}$ & $\begin{array}{c}10.075 \\
-12.106 \\
-4.137 \\
-4.968 \\
2.160\end{array}$ & $\begin{array}{l}0.000 \\
0.000 \\
0.000 \\
0.000 \\
0.031\end{array}$ \\
\hline $\begin{array}{l}S_{\text {REFC }} \\
\text { (Mean of slope from REFC to MATH) }\end{array}$ & $\begin{array}{c}\text { EXPT } \\
\text { PMOD } \\
\text { FACT } \\
\text { DELG }\end{array}$ & $\begin{array}{c}1.000^{\mathrm{a}} \\
-2.634^{\star *} \\
-1.820^{\star} \\
-0.256\end{array}$ & $\begin{array}{l}0.000 \\
0.665 \\
0.800 \\
0.320\end{array}$ & $\begin{array}{c}999.000 \\
-3.959 \\
-2.275 \\
-0.801\end{array}$ & $\begin{array}{c}999.000 \\
0.000 \\
0.023 \\
0.423\end{array}$ \\
\hline $\begin{array}{l}\text { SPRAG }_{\text {Pan }} \\
\text { (Mean slope from PRAG to MATH) }\end{array}$ & $\begin{array}{c}\text { EXPT } \\
\text { PMOD } \\
\text { FACT } \\
\text { DELG }\end{array}$ & $\begin{array}{c}2.433 \\
0.428 \\
-3.576^{\star *} \\
-2.403^{*}\end{array}$ & $\begin{array}{l}1.278 \\
1.279 \\
1.156 \\
1.175\end{array}$ & $\begin{array}{l}1.905 \\
0.334 \\
-3.095 \\
-2.045\end{array}$ & $\begin{array}{l}0.057 \\
0.738 \\
0.002 \\
0.041\end{array}$ \\
\hline Residual & $\begin{array}{l}\text { MATH } \\
S_{\text {ACTV }} \\
S_{\text {THEO }} \\
S_{\text {RECT }} \\
S_{\text {PRAG }}\end{array}$ & $\begin{array}{c}5.682^{\star *} \\
2.999^{\star *} \\
2.186^{\star *} \\
0.001 \\
1.260^{\star *}\end{array}$ & $\begin{array}{l}1.265 \\
0.532 \\
0.629 \\
0.003 \\
0.409 \\
\end{array}$ & $\begin{array}{l}4.492 \\
5.638 \\
3.476 \\
0.417 \\
3.081 \\
\end{array}$ & $\begin{array}{l}0.000 \\
0.000 \\
0.001 \\
0.677 \\
0.002\end{array}$ \\
\hline
\end{tabular}

Note: 1) ${ }^{\text {a }}$ fixed value as one to be the reference group, 2$)^{*} p$-value $<0.05,{ }^{* *} p$-value $<0.01$.

mismatching with the PMOD $\left(b_{P M O D}=-2.555\right)$ and the FACT $\left(b_{\text {FACT }}=-0.978\right)$ teachers. The REFC students were mismatching with the PMOD ( $\left.\mathrm{b}_{P M O D}=-2.596\right)$ and the FACT $\left(b_{F A C T}=-1.820\right)$ teachers. The PRAG students were matching with the EXPT $\left(b_{\text {EXPT }}=-3.576\right)$ and the DELG $\left(b_{D E L G}=-2.403\right)$ teachers.

\section{Conclusion}

Although the learning styles and teaching styles have been broadly researched, little knowledge was known about the Thai students' learning styles and mathematic teachers' teaching styles. The purposes of this study were to explore the students' learning styles and teachers' teaching styles and to study effects of learning styles and teaching styles on mathematics achievements. The research results showed various magnitudes and patterns of matching and mismatching between learning and teaching styles on achievements. It was implied that the suitable theoretical framework could be explained by 


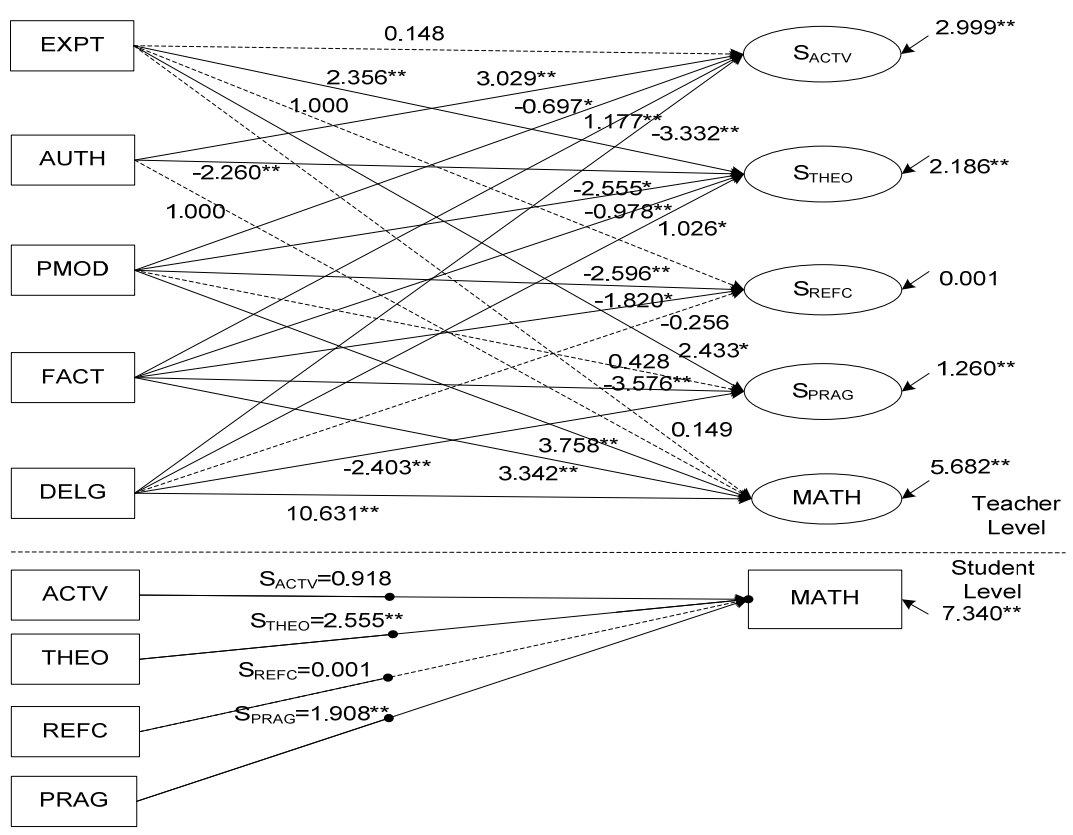

Figure 1. Multilevel regression model of effects and interaction effects of learning and teaching styles on mathematic achievements.

the individual difference of both the Thai students and the mathematics teachers. The researcher has surprisingly noted narrow percentage between each learning style, that is, approximately $25 \%$. Whereas, it was obvious in the different percentage for mathematics teachers' teaching style, which was inclined to be the facilitator and the expert styles. These were related to a number of prior studies that had found a variety of learning and teaching styles. This is a good reason to support teachers to avoid the two mistakes to assume that the model of teaching is a fix or inflexible formula and that each learner has a fix style of learning (Joyce and Well, 2004).

In addition, the researcher was not surprised about the theorist and the pragmatist students that appeared to be dominant in mathematic learning. By definition, the theorist and the pragmatist students, were commonly strong in reasoning and concept in response to mathematics, science and engineering, which were fields of study that are abstract, logical, and reasoning relying on a content based learning. On the other hand, the activist and the reflector students were strong in activity and experience based learning (Honey and Mumford, 1982). These abilities are directly beneficial in mathematics learning by nature. These results were relative to the studies of Orhun (2012) Okura and Bahar (2010) Peker (2009) and Ozgen (2013) that have explained students' mathematic outcome by Kolb's ELM and found that the Assimilator and the Converge (the Theorist and the Pragmatist in Hunny and Mumford's concept respectively) had higher mathematic self-efficacy and lower mathematic anxiety than those of the rest of the two groups of learning styles. The reflector student in particular, the only one learning style, was affected negatively from all teaching styles. They should be closely observed on their learning from all mathematics teachers. This is the weakest and most sensitive learning style, and the students received the teaching instruction bias from all teachers. In relation to this problem, the researcher hypothesized that their learning method was accentuated in data collection, observation, and summarization which might be contrast to the nature of the subject. Hyman and Rosoff (1984) suggested the related factors to investigate the relationship between how teachers teach and how students learn which consisted of the teacher, student, and subject matter. For this reason, the activist and the reflector styles might be dominant in other subjects relevant to where their capability belongs.

As for teaching styles, the three teaching styles (delegator, personal model, and facilitator) have significantly positive effects on mathematic achievements, especially the DELG style. These three groups have the common characteristic of encouraging a student's response to their initiative and support students' need to learn independently (Grasha, 1996). Hugh (2011) described these manners as a progressive teacher type who support their students and had an active role or learnercenter approach. Not only can they promote academic outcomes, but also the progressive teachers foster the positive relationship in the classroom and create more flexible activities in learning processes (Education, Audiovisual, and Culture Executive Agency, 2011).

Now that there are more details than ever, the matching results have strongly confirmed the interaction effect on students' achievement for every learning and teaching style. The results showed style by style matching and mismatching both positively and negatively. This could be 
explained by Grasha's suggestion (2002 p. 93) about "the instructional method bias" in the classroom management system which makes inequality for learning. Various patterns were found to rely on the dominant style of teachers and students. According to the main results, the six pairs of matching consisted of the theorist and the pragmatist students matching with the expert teacher; the activist student matching with the formal authority and the facilitator teachers; and the activist and the reflector students mismatching with the formal authority teacher. These matching and mismatching were congruence with research hypotheses. In contrast, the rest of the twelve pairs of matching were different from the research hypothesis in the manner of the direction of the interaction and statistical significance. This may be incongruence due to specific subject, specific groups of students and teachers in specific culture in Thailand. All these different conditions were the important influential factors to consider how learning and teaching styles interact (Hyman and Rosoff, 1984; Dunn and Dunn, 1992). It should be underlined about the reflector achievement mismatching with all the teaching styles. There may be three main reasons to explain. Firstly, the mathematic nature and the logical and content-based subject were the impediment for the students with reflector learning style who were strong in listening and elaborately thinking. No matter how the teaching styles were implemented, it is still difficult to enhance mathematic achievement for this group if they lack the necessary basic content in the field. Secondly, in Thai mathematic classrooms, almost all of the teaching methods emphasize lectures, and individual students are given limited time, which was in contrast to the reflector who prefer to listen and to observe for their learning (Honey and Mumford, 1996; Herasymowych, 1997)

In conclusion, each learning style and teaching style had effects on mathematics achievement of students unequally, both positively and negatively. Also, these effects could be changed when interaction effects are considered. In these cases, $76.47 \%$ of students were affected. These can be divided in $30.77 \%$ positive and $69.23 \%$ negative effects, by approximation. Based on the results, the researcher have concerns about the importance of matching research areas to give more necessary details for implementations in the classrooms and schools based on many educators' and researchers' suggestions (Hayman and Rosoff, 1984; Peacock, 2001; Visser et al., 2006; Naimie et al., 2010; Ghada et el., 2011).

\section{Recommendations}

Based on the evidences, the students should be responsible for their own learning. Effects of both learning and teaching styles distinctly appeared in every classroom system. Most instructors always teach the ways they like, but they neglect to consider the students' information for learning management. The researchers strongly supported to use the information from the research results urgently. This can be applied step by step. Firstly, the researcher strongly agreed with what many educators have been suggesting to impulse teachers' awareness of students' different learning styles, and this is their direct responsibility to create equality for their students. It is the most important to take the knowledge of learning and teaching styles as an important part in learning achievement and problem solution. Obviously, teachers should accommodate students' learning styles to design lesson plans before the first semester begins every academic year. However, the progressive teachers affected more on mathematics achievements than the traditional teachers. The traditional teachers, especially the experts, affected positively on students' learning mathematics. This implied the important role of the expert for all learning styles even if the expert did not significantly affect directly on mathematics. Also, it should be noted for teachers to oversee, guide, and focus on facts in mathematics content to prepare their students. As the learning-center students construct their basic concept by themselves, it is not a good choice for enhancing mathematic achievement, but it might be different in other subjects. Secondly, it is hardly possible for teachers to use all teaching methods in any one lesson, and they could not select or plan to teach the right student for positive matching of their own teaching style in the classroom. Changing one's teaching style may not benefit enough students and may limit the instructor's ability to impart all the information in the classroom. The administrators should support their teachers' realization of teaching and learning styles to share the experience between teaching styles, enhance using various media types, and cover learning styles of students in the classroom. Finally, the school administrators and policy makers should rapidly help the teachers, especially in the personal model style, to understand how to adapt their teaching method or use more educational media for student learning process, and to help the students especially in the reflector students who received negative effects from matching more than the others in mathematics. For future studies, the researcher believe that the effects of learning and teaching styles not only appeared in mathematics but also in other important subjects based on what the prior literature reviews have implied the different effects from matching or mismatching in different subjects. Even though they used different theoretical frameworks, they did not imply research results in the students and teachers in Thailand because of the many different factors in the Thai culture. Furthermore, it may be a good shortcut if the future study directs towards mismatched student for elucidating half of the Thai students' improvement, such as the alternative educational media, assessment, or homework characteristics for supplementing the mismatched students efficiently.

\section{Conflict of Interests}

The authors have not declared any conflict of interests. 


\section{ACKNOWLEDGEMENT}

This study was a supported research fund by the Thai Research Fund (TRF), the office of Higher Education Commission (OHEC), and Mahasarakham University (MSU). The author gratefully acknowledge Prof. Dr. Peter Honey, Prof. Dr. Alan Mumford, and Prof. Dr. Antony Grasha to inspire and give different views and consent for the translation of the Learning Style Questionnaire (LSQ) and the Teaching Style Inventory (TSI) into the Thai version. In addition, the authors would like to acknowledge the ninth-grade students, the teachers and the administrators for their willing consent of the research data.

\section{REFERENCES}

Akdemir O, Koszalka TA (2008). Investigating the relationships among instructional strategies and learning styles in online environments. Computers and Educ. 50(4):1451-1461.

Alhussain AM (2012).Identifying teaching style: The case of Saudi College EnglishLanguage and Literature Teachers. English Language Teaching. 5(8):122-129.

Allinson CW, Hayes J (1988). The learning styles questionnaire: an alternative to Kolb's inventory? J. Manage. Stud. 25:269-281.

Altun F, Yazici H (2010). Learning styles of the gifted students in Turkey. Procedia Social Behavioral Sci. 9:98-202.

Beck CR (2001).Matching teaching strategies to learning style preferences. The Teacher Educator, 37(1):1-15.

Butler KA (1988). How kids learn: what theorists say. Learning17:30-43.

Cano J, Garton BL, Raven MR (1992).Learning styles, teaching styles and personality styles of preservice teachers of agricultural education. J. Agric. Educ. 46-52.

Cassidy S (2004). Learning styles: an overview of theories, models, and measures. Educ. Psychol. 24(4):419-444.

Damrongpanit S, Reungtragul A (2013). Matching of learning styles and teaching styles: Advantage and disadvantage on ninth-grade students' academic achievements. Educ. Res. Rev. 8(20):37-1947.

Duff A (2001). A note on the psychometric properties of the Learning Styles Questionnaire (LSQ).Accounting Educ. 10(2):185-197.

Education, Audiovisual, and Culture Executive Agency (2011). Mathematics Education in Europe: Common Challenges and National Policies.

Entwistle NJ (1991). Cognitive style and learning. In: Merjoribanks, The Foundations of Students' Learning(pp.139-145). NSW, Australia: Pergamon Press.

Felder EM, Silverman LK (1988). Learning styles and teaching styles in engineering education. Eng. Educ. 78:18-23.

Felder RM, SpurlinJ(2005). Applications, reliability and validity of the index of learning styles. Int. J. Eng. Educ. 21(1): 03-112.

Ford N, Chen SY (2001). Matching/mismatching revisited: an empirical study of learning and teaching styles. Br. J. Educ. Technol. 32(1): 522.

Ghada S, Rima B, Nahla Nola B, Mona N (2011). A match or mismatch between student and teacher learning style preferences. Int. J. English Linguist. 1(1):162-172.

Grasha AF (1996). Teaching With Style. Pittsburgh: PA: Alliance Publishers.

Grasha AF (2002). Teaching with Styles: A Practical Guide to Enhancing Learning by Understanding Teaching and Learning Styles. San Bernarino, CA: Alliance.

Hayes J, Allinson CW (1996). The implications of learning styles for training and development:A discussion of the matching hypothesis. Bri. J. Manage. 7(1):63-73.

Herasymowych M (1997).Understanding and Working with Learning Styles: Theory andPractice. Edmonton, Alberta: MHA Institute, Inc.

Honey P, Mumford A (1996). The manual of learning styles. Maidenhead, Berkshire: Peter Honey.

Hyman R, Rosoff B (1984). Matching learning and teaching styles: the jug and what's in it. Theory Into Pract. 23(1):35-43

Joyce B, Well M (2004). Model of Teaching. New Delhi: Prentice-Hall of India.

Khandaghi MA,Farasat M (2011). The effect of teacher's teaching style on students' adjustment. Proc. Soc. Behav. Sci. 15:1391-1394.

Kinshuk Liu TC, Graf S (2009). Coping with mismatched courses:students' behavior and performance in courses mismatched to their learning styles. Educ. Teach. Res. Dev. 57:739-752.

Kolb DA (1984).Experiential learning: Experience as the source of learning and development. New Jersey: Prentice Hall.

Lage MJ, Platt GJ, Treglia M (2000).Inverting the classroom: A gateway to creating an inclusive learning environment. J. Econ. Educ. 31(1):30-43.

Naimie Z, Siraj S, Piaw CY, Shaghili R, Abuzaid RA (2010). Do you think your match in heaven? Teaching styles/learning styles match and mismatch revised. Procedia Social Behavioral Sci. 2: 349-353.

Nor Azan MZ (2006).Using multimedia for effective teaching: Matching instructions to student's learning styles. Proceedings of the International Conference on Information and Communication Technologies, April 24-28, 2006, Damascus, Syria pp.595-600.

Okura M, Bahar HH (2010). Learning styles of primary education prospective mathematics teachers; states of trait-anxiety and academic success.Proc. Soc. Behav. Sci. 2:632-3637.

Orhun N (2012). The relationship between learning styles and achievement in calculus course for engineering students.Procedia Soc. Behav. Sci. 47:638-642.

Ozgen K (2013). An analysis of high school students' mathematical literacy self-efficacy beliefs in relation to their learning styles.AsiaPacific Educ. Res. 22:91-100.

Pavio A (1971). Styles and strategies for learning. Bri. J. Educ. Psychol. 46:128-48.

Peacock M (2001). Match or mismatch? Learning styles and teaching styles in EFL. Int. J. Appl. Linguist. 11:1-20.

Peker M (2009).Pre-service teachers' teaching anxiety about Mathematics and their learning styles.Eurasia J. Math. Sci. Technol Educ. 5(4):335-345.

Peterson ER, Rayner SG, Armstrong SJ (2009). Researching the psychology of cognitive style and learning style: Is there really a future? Learn. Individ. Diff. 19:518-523.

Rahimi M, Asadollahi F (2011). On the relationship between Iranian EFL teachers' classroom management orientations and teaching styles.Proc. Soc. Behav. Sci. 31:49-55.

Rayner S, Riding R 1997).Towards a categorization of cognitive styles and learning styles. Educ. Psychol. 17:5-27.

Reid J (1996). A learning styles unit for the intermediate ESL/EFL writing classroom. TESOL J. Autumn. pp.42-47.

Sriphai S, Damrongpanit S, Sakulku J (2011). An investigation learning styles influencing mathematics achievement of seventh-grade students. Educ. Res. Rev. 6(15):835-842.

Tulbure C (2012). Investigating the relationships between teaching strategies and learning styles in higher education. Acta Didactica Napocensia 5(1):65-74

Vaughn L, Baker R (2001). Teaching in the medical setting: balancing teaching styles, learning styles and teaching methods. Medical Teacher. 23(6):610-612.

Vermunt JD (1994). 'Design principles of process-oriented instruction'. In EP.C.M.de Jong and B.H.A.M. Van Hour Wolters (Eds.), Processoriented instruction and learning from text (pp. 15-26) Amsterdam: VU University Press.

Vermunt JD, Verloop $\mathrm{N}$ (1999).Congruence and friction between learning and teaching.Learn. Instruction 9:257-280.

Visser S, McChlery S, Vreken N (2006). Teaching styles versus learning styles in the accounting sciences in the United Kingdom and South Africa: a comparative analysis. Meditari Account. Res. 14(2):97-112.

Witkin HA (1962). Psychological Differentiation: Studies of Development. New York: Wiley.

Yazicilar ö,Güven B (2009). The effects of learning style activities on academic achievement, attitudes and recall level. Procedia Social and Behavioral Sciences. 1:2578-2583.

Zhang LF (2005). Does teaching for a balanced use if thinking styles enhance students' achievement? Pers. Individ. Diff. 38:1135-1147. 